\title{
Thermal Analysis of Asphalt Concrete Pavements Heated with Amorphous Metal Technology
}

\author{
Cesare Sangiorgi, Cecilia Settimi, Piergiorgio Tataranni (iD, Claudio Lantieri, \\ and Solomon Adomako \\ Department of Civil, Chemical, Environmental and Materials Engineering, University of Bologna, Bologna, Italy \\ Correspondence should be addressed to Piergiorgio Tataranni; piergiorg.tataranni2@unibo.it
}

Received 12 August 2018; Revised 19 November 2018; Accepted 4 December 2018; Published 13 December 2018

Academic Editor: Antonio Caggiano

Copyright (c) 2018 Cesare Sangiorgi et al. This is an open access article distributed under the Creative Commons Attribution License, which permits unrestricted use, distribution, and reproduction in any medium, provided the original work is properly cited.

\begin{abstract}
Undoubtedly, the most commonly used method for road maintenance includes the use of winter service vehicles to clear thoroughfares of snow and the spraying of chemicals to prevent ice formation on the road surface. The application of these traditional methods on road and airport pavements possesses numerous environmental, organizational, and technical challenges. To overcome these critical issues, new nontraditional technologies that act within the pavement, thereby increasing its temperature, have been developed. In relation to the heat source used, these are classified into chemical and physical methods. The purpose of this research is to study the temperature variation under the thermal transient process produced by the action of the physically heating device installed in the road pavement. The heating device is a ribbon, made of amorphous material, which is able to produce heat to warm up the pavement and its surface. Based on its principle of operation, it is classified among the nontraditional physical methods for the treatment of snow and ice. In this work, the performance of the heating ribbons on an experimental site at the G. Marconi International Airport in Bologna (Italy) is presented.
\end{abstract}

\section{Introduction}

In winter, the management of snow and ice disposal is one of the main problems of road pavement maintenance, with multiple negative effects on roads, railways, and airports [1]. These atmospheric events are hardly foreseeable and dangerous since they affect user safety, by reducing skid resistance of pavements. In the roadway, the rate of accidents due to ice formation is 4-5 times greater than what is observed after spraying interventions by winter service vehicles [2]. Regarding the safety of airport activities, surface skid resistance is of great importance, both in dry and wet conditions, because of the hazards associated with aircrafts ground maneuvers. From a business management point of view, there could be serious downturns of airport activities such as the cancellation of departing flights and diversion to other airports of incoming traffic [3]. The road infrastructure becomes the next available and widely used mode of transport, when there is travel uncertainty due to weather conditions, and this unquestionably increases travel times on land transport, resulting in poor level of service and compromise the quality of travel comfort.

Ice and snow are also a source of degradation on paved surfaces [4]. The phenomenon of thermal cracking is manifested as a result of a sharp decrease in temperature (low-temperature cracking) or because of the fatigue induced by repeated thermal cycles (thermal-fatigue cracking) [5]. In flexible pavements, the low-temperature behavior of asphalt concrete (AC) is related to the chemical and rheological properties of the adopted bitumen [6]. Generally, at low temperatures, this behavioral pattern facilitates the loss of binder repair ability and, consequently, causes a faster deterioration according to the fatigue-cracking phenomenon $[7,8]$. Furthermore, in both flexible and rigid pavements, the porous structure of concrete and AC results in a degradation of the rolling surface when subjected to freezing 
and thawing cycles. In fact, the capillary pores of both mixtures can hold water, but due to the lowering of the temperature below $0^{\circ} \mathrm{C}$, the water becomes ice with a volume increase of about 9\% [9]. When this happens, it cannot be housed inside the cavities of the concrete matrix, and therefore, tensions are created, resulting in a damage of the material. This is especially observed if the frost action alternates repeatedly with the thawing.

Traditional methods for winter maintenance include the use of winter service vehicles to eliminate snow accumulation on pavement and the spread of chemicals to prevent ice formation. The direct application of these methods on the pavement of roads and airports pose a number of environmental, organizational, and technical challenges. Winter maintenance is an increasingly costly item of the annual agency budget and may lead to environmental impact [10]. It is worth noting that spreading of anti-ice chemicals (sodium chloride, calcium chloride, and magnesium chloride), which represent the most common technique for winter maintenance, causes progressive deterioration of the paved surface, due to chemical interactions with bituminous layers or concrete ones. To overcome these challenges, nontraditional technologies are being developed, which act within the pavement and increase its temperature.

Application of the chemical method requires the addition of specific additives to the asphalt concrete. For example, common road-based chlorine or special materials (normally $3 \%$ and $5 \%$ of the weight of the aggregates) can be used depending on the operating temperatures envisaged at the design stage. These additives lower the freezing temperature of the water on the paved surface and slow down the formation of ice crystals [11]. However, in extreme weather conditions, no substantial differences are visible because temperatures fall drastically; therefore, the product's response becomes negligible, resulting in no practical observations.

Another method is to act directly on the pavement with the introduction of new constituent materials able to reduce the formation of ice on the surface. Some researchers developed a superhydrophobic coating (SC) on the asphalt pavement, which was provided for good antiicing performance, contributing to traffic safety in adverse weather conditions $[12,13]$. Other studies evaluated the potential application of crumb rubber and diatomite for the production of anti-icing asphalt mixtures with positive outcomes [14]. As for physical methods, the aim is to produce a heating effect on the pavement surface by means of switching on the heat source installed within it. There are two different systems useful for pavement heating: the hydronic systems and the electric heating system. In the hydronic systems, a heated fluid circulates within the pipes installed in the bituminous conglomerate or concrete, transferring heat by conduction. According to Eugster et al, this system can be differentiated based on the heat source from which the fluid is heated, that is, geothermal waters, geothermal heat pumps, ground source heat pump system, and waste heat [15-19]. Finally, the electric heating system warms up the pavement surface, thanks to the heat generated by the electrical current in the cables. This paper presents the evaluation of the temperature variation under the thermal transient process produced by the action of the heating technologies installed in a bituminous pavement. The heating ribbon presented can be classified among the pavement heating physical methods, thanks to the heating power produced by the passage of electricity within the conductor [20]. The experimental site was created at G. Marconi International Airport in Bologna. The choice of this site depends on the fact that the product is designed to be used in circumscribed areas where a fast pavement heating is required. The problem is indeed very important in airports where some researchers are developing new methods, based on infrared (IR) thermography, to evaluate and compare the anti-icing performance, i.e., the ability to delay the reformation of ice, of runways and taxiways deicing/antiicing fluids (RDF) under icing precipitation [21].

\section{Experimental Work}

2.1. Heating System. The heating device is a $3.5 \mathrm{~cm}$ wide flexible ribbon, laid under the bituminous surface layer (Figure 1). It consists of a conductive element in the form of a nickel-based amorphous metal band, $25 \mu \mathrm{m}$ thick and $2.5 \mathrm{~cm}$ wide. The amorphous element is coated with a lowdensity polyethylene double layer coat of $50 \mu \mathrm{m}$ thickness. Two copper cables with high-density polyethylene coating are placed at the sides of the conductor. These are the return cables, which are connected from the opposite ends of the conductor to the front of the tape, in order to close the circuit. The set of electrical return cables and the conductive element are enclosed in another protective cover, made of $50 \mu \mathrm{m}$ thick aluminum and a coating of $12 \mu \mathrm{m}$ thick polyester.

The ground wire is directly in contact with the aluminum throughout the length of the ribbon to dissipate any harmful electrical current. All the elements are coated with an outer layer of nominal thickness of $1 \mathrm{~mm}$ made of lowdensity polyethylene. For safety purposes, the outer polyethylene layer is treated with a flame retardant product. Finally, the system is connected to an electrical junction box, with a proper protective layer, from the end of the ribbon. This layer is also coated to a thickness of $1.4 \mathrm{~mm}$ and is made of materials that isolate the connections. Once connected and wired, the system forms a closed-loop circuit with an electric resistance offered by the metallic amorphous element (Figure 1). The ribbon in a serpentine form and is laid under the bituminous top layer or deep enough to ensure adequate heating of the pavement surface. In Figure 1, the ribbons are covered by a thin layer of cold asphalt, to protect the system to the bottom layer before the laying of the new hot asphalt.

A basic parametric design of the system is the spacing span between two consecutive elements in the serpentine, which affects both energy consumption and performance. An interaxle spacing of $20 \mathrm{~cm}$ is designed to meet the project requirements in terms of power required for each heated square meter. 


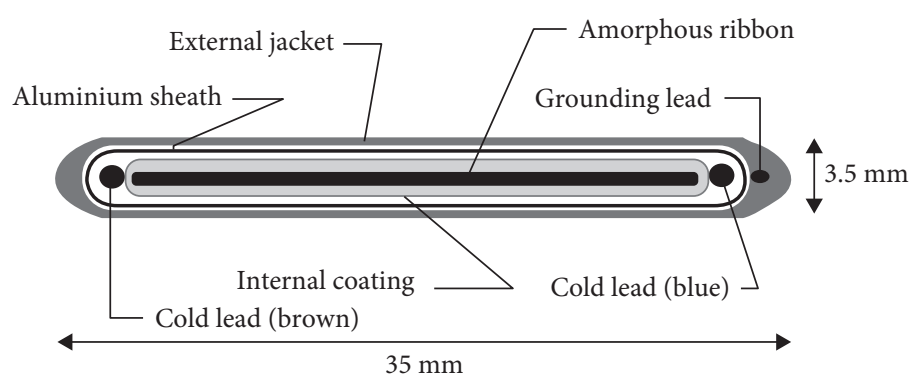

(a)

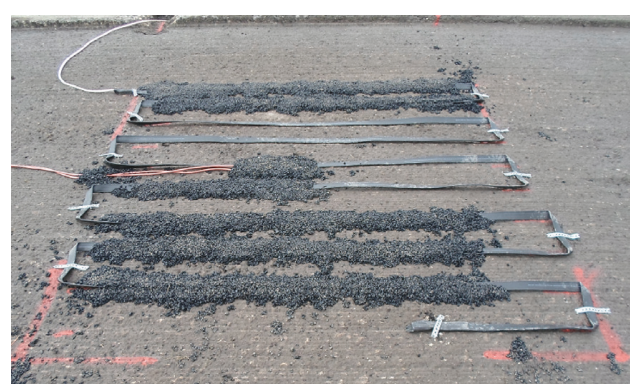

(b)

FIgURE 1: Ribbon section and laying of the heating element (protective cold asphalt on the top).

2.2. Trial Field. The experimental site was set up in a section of the service road close to the General Aviation Terminal at the G. Marconi International Airport in Bologna. The area was subdivided into four sub-areas, each $4 \mathrm{~m}$ long and wide. Two ribbons were installed at the two external areas, at $6 \mathrm{~cm}$ and $10 \mathrm{~cm}$ depth from the pavement surface (R6 and R10). In addition to these two areas, two other sections without heating ribbons were constructed for comparative analysis (NR6 and NR10) (Figure 2). The depth of $6 \mathrm{~cm}$ was selected so that wearing course milling $(3-4 \mathrm{~cm})$ could not affect the ribbon, while the $10 \mathrm{~cm}$ depth was chosen as the maximum practical one for the product installation.

For the construction of the trial field, the existing pavement was milled until sufficient depth was achieved for the positioning of the ribbons and then paved with a new bituminous layer. The top asphalt layer were laid and compacted to a final thickness of $10 \mathrm{~cm}$ for R10/NR10 and $6 \mathrm{~cm}$ for R6/NR6. A high-modulus asphalt concrete for small grading binder layer with high-workability-modified bitumen was used in this trial field.

\subsection{Thermal Data Management and Acquisition System.} The experimental site was set up to verify the operation of the heating ribbons on a real scale. To this end, specific tests were carried out to evaluate the melting of snow and ice on the pavement in relation to its heating point and the possibility of preventing their formation. For the field test, specific temperature measurement system consisting in a series of the negative temperature coefficient (NTC) thermistors was developed. The resistors used have particular electrical components and have designed to provide specific resistance to the passage of the electric current. NTC thermistors provided real-time temperatures on multiple points in the pavement and the data transmission to a processing device. These thermistors are made of semiconductor materials such as metal oxides (iron, nickel, and cobalt). In this way, the resistance decreases as the temperature increases and are characterized by a NTC. In all experimental areas, the sensors were installed at different depths to evaluate the temperature distribution within the pavement (Figure 3 and Table 1). The temperature measurement system carried out for the trial field consists of 21 NTC thermistors installed at 15 measuring points: 8 of them superficial $(2 \mathrm{~cm}$ and $0.5 \mathrm{~cm}$ deep $), 6$ in depth $(6 \mathrm{~cm}$ and
$10 \mathrm{~cm}$ deep), and 1 out of the pavement $1.5 \mathrm{~m}$ height to measure air temperature (Table 1).

In the deep measuring points (S4, S5, S7, S8, S11, and S13), two sensors were installed for each position in order to guarantee the collection of data. In the surface measuring points, single sensors were installed. To protect the thermistor from thermal and mechanical shocks, each of them was inserted into a stainless steel cylinder. A cold asphalt layer laid for positioning purposes also provided a significant protective contribution. Surface sensors, instead, were installed right below the asphalt surface layer. These were placed in a cut in the layer running from the measuring point to the pavement edge and successively sealed with bituminous emulsion.

Thermistors have a temperature sensitivity of $1 / 10^{\circ} \mathrm{C}$ $( \pm 0.1)$. They are set up in a way that if no significant temperature variation is detected, the temperature measurement takes place every 3 minutes. Conversely, a temperature variation above the tenth of degree makes the thermistor record a new measured data.

\section{Data Recording and Analysis}

The analysis of the performance of the heating system consists of 3 consecutive phases:

(1) The temperatures of the switched-off ribbon were recorded and studied to verify the operation of the measuring and online data transmission system.

(2) A series of manual activation tests of the system were carried out to verify the performance of the ribbons and to develop an operational protocol.

(3) The system was tested with remote boot to configure the automatic set up.

3.1. Analysis of Data Acquired by Manual Operation. The heating system was remotely activated, from 5:00 am to 1:00 pm on alternate days to avoid any delayed thermal effects. During this period, the surface temperature in the NR areas ranged between 3 and $5^{\circ} \mathrm{C}$. The analysis of the data recorded by the sensors placed on a vertical alignment has allowed the study of the temperature variation along the thickness of the asphalt layer. 


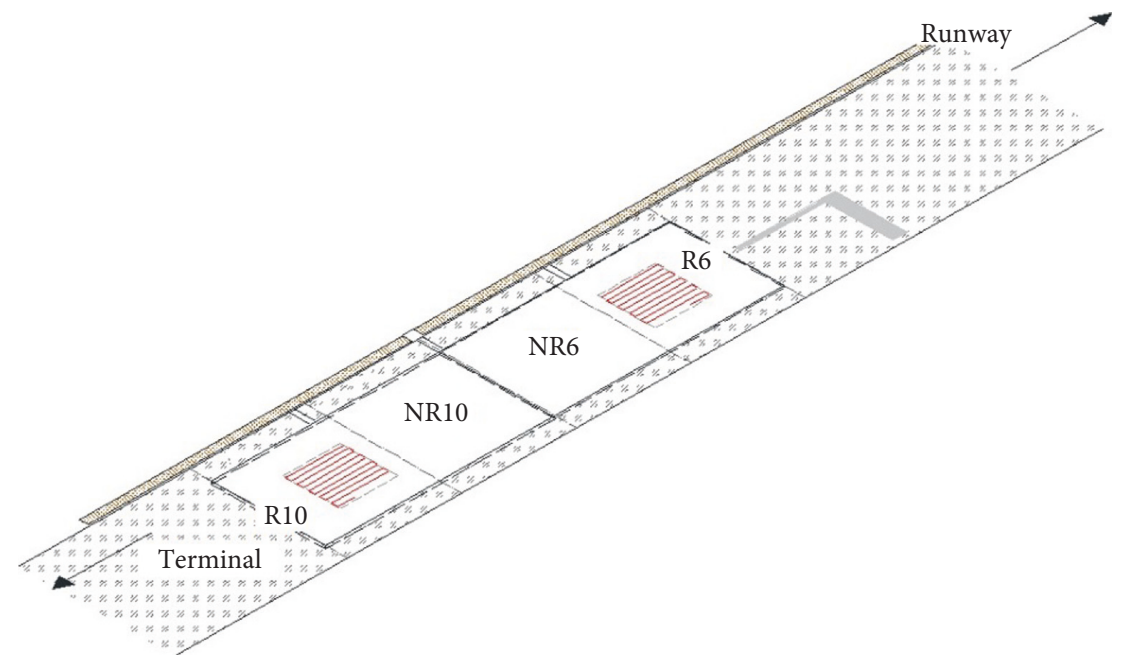

Figure 2: Scheme of installation in the trial field.

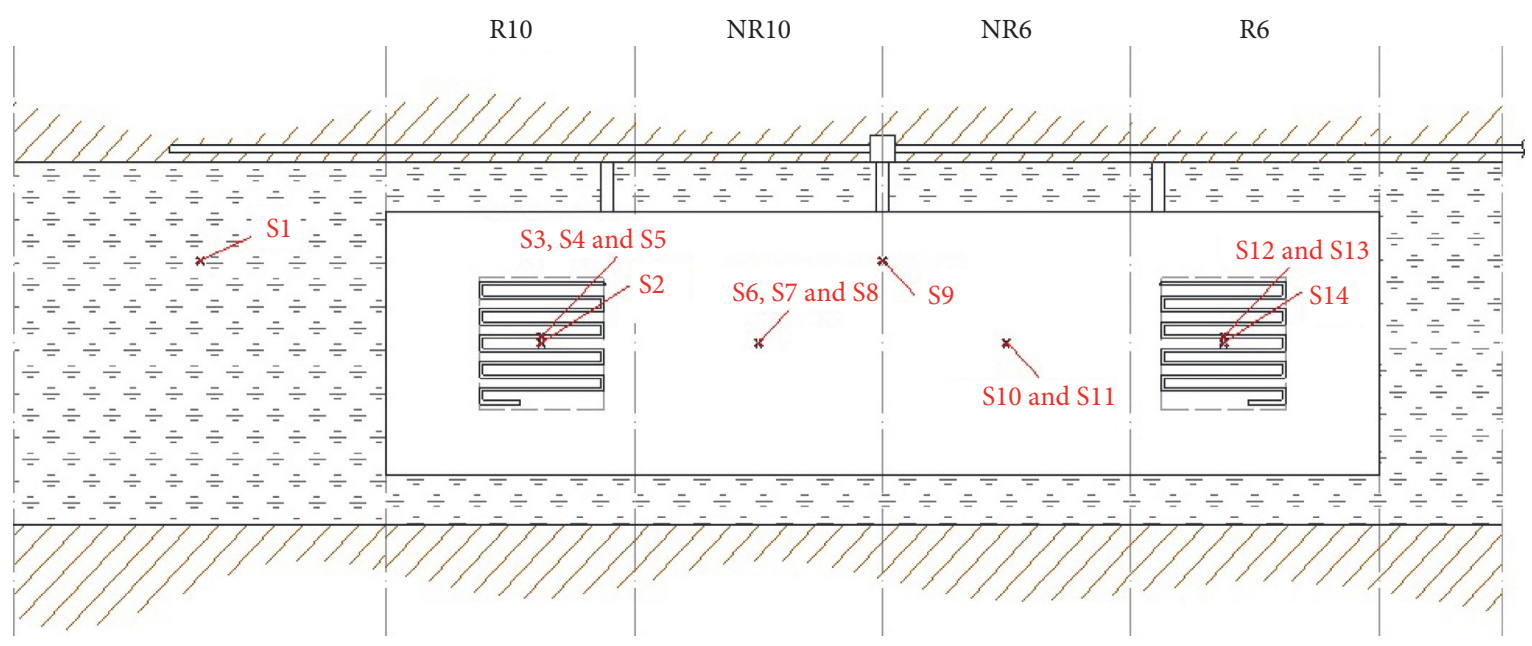

Figure 3: Position of thermistors in the trial field. Note that S2 and S14 are in-between ribbons.

Figure 4 shows how the ribbons were able to cause an increase in the deep and surface layer temperatures in both configurations, i.e., the ribbon at a depth of $6 \mathrm{~cm}$ and $10 \mathrm{~cm}$. The heat from the ribbon reaches all thermistors with delays and gradients related to their relative distance from the ribbon and from the pavement surface. The fastest temperature change was recorded in the system during its first hour of activation. In this time interval, the average temperature rate was $0.018^{\circ} \mathrm{C} / \mathrm{min}$ at the surface and $0.16-$ $0.18^{\circ} \mathrm{C} / \mathrm{min}$ at the deeper ribbons.

Considering the data provided by the sensors right on the ribbons, S5 and S13, and the corresponding sensors installed in the two areas without the heating system (the same depth), it was possible to calculate the heating contribution offered by the system itself. In both R10 and R6 areas, this contribution increased until it reached its maximum level at 1:00 pm to a stable temperature of approximately $20.8^{\circ} \mathrm{C}$ in $\mathrm{R} 10$ and $19.4^{\circ} \mathrm{C}$ in R6 (Figure 5). The sensors in the areas without the ribbon remained unaltered and ranged between 3.6 and $4.8^{\circ} \mathrm{C}$.
The same analysis was applied to the surface temperature measurements. The sensors data at the surface points S3 and S12 (respectively, in the R10 and R6 areas) were compared with those placed in the corresponding points in the areas without ribbons (NR10 and NR6). It was recorded that, in R10, the heating contribution initially increased and then stabilized in the last hours of activation with a peak value close to $8.0^{\circ} \mathrm{C}$. In R6, the heating contribution offered by the system had a similar trend with a peak value just above $7.0^{\circ} \mathrm{C}$ (Figure 6).

Finally, the surface distribution of temperatures with a distance between adjacent ribbon elements of $20 \mathrm{~cm}$ in both $\mathrm{R} 10$ and R6 areas were analyzed. The values provided by the surface sensors positioned on the vertical axis above the ribbon (S3 in R10 and S12 in R6) and by the sensors at the mid-depth (S2 in NR10 and S14 in NR6) showed a maximum difference in $\mathrm{R} 10$ equal to $1.3^{\circ} \mathrm{C}$ and values in $\mathrm{R} 6$ ranging between -0.2 and $0.2^{\circ} \mathrm{C}$ (Figure 7). On this basis, it can be concluded that the surface temperature distribution can be considered uniform in both pavements, being the R6 surface more evenly warmed. 
TABLE 1: List of sensors and their locations.

\begin{tabular}{lccc}
\hline Point & Area & Nominal depth & Sensor \\
\hline S1 & Existing pavement & $0.5 \mathrm{~cm}$ & T01 \\
S2 & R10 & $2.0 \mathrm{~cm}$ & T02 \\
S3 & R10 & $2.0 \mathrm{~cm}$ & T03 \\
S4 & R10 & $6.0 \mathrm{~cm}$ & T04 \\
& & & T05 \\
S5 & R10 & $10.0 \mathrm{~cm}$ & T06 \\
S6 & NR10 & $2.0 \mathrm{~cm}$ & T07 \\
S7 & NR10 & $6.0 \mathrm{~cm}$ & T08 \\
& & & T09 \\
S8 & NR10 & $10.0 \mathrm{~cm}$ & T10 \\
S9 & Joint NR10-6 & $0.5 \mathrm{~cm}$ & T12 \\
S10 & NR6 & $2.0 \mathrm{~cm}$ & T13 \\
S11 & NR6 & $6.0 \mathrm{~cm}$ & T14 \\
S12 & R6 & $2.0 \mathrm{~cm}$ & T15 \\
S13 & R6 & $6.0 \mathrm{~cm}$ & T16 \\
S14 & R6 & $2.0 \mathrm{~cm}$ & T18 \\
S15 & Electric box & - & T19 \\
\hline
\end{tabular}

3.2. Analysis of Data Recorded in the Automatic Mode. The final analysis focused on the automatic activation mode. This system allows autonomous activation of the heating ribbons when the temperature falls below a set threshold. This value corresponds to the surface temperature that might reduce the safety of the infrastructure due to ice formation. The online remote activation protocol foresees the use of the following:

(i) A temperature reference sensor: surface thermistor placed on the vertical line above the ribbon (S3 in R10 and S12 in R6)

(ii) An activation set point at a temperature of $3^{\circ} \mathrm{C}$

(iii) An hysteresis range of $1^{\circ} \mathrm{C}$

Between the 5th and the 12th of February 2016 and in 3 different days, some drop in temperature was recorded at the trial site reaching values below the threshold. These were sufficient to activate the system (Figure 8).

In the temperatures recorded on February the $5^{\text {th }}$, the $10 \mathrm{~cm}$ deep ribbon was turned on at $6.05 \mathrm{am}$. This activation caused an $\mathrm{R} 10$ surface temperature increase of $2.0^{\circ} \mathrm{C}$ during the activation and a temperature of $17.1^{\circ} \mathrm{C}$ on the ribbon. The average thermal rate at the pavement surface was equal to $0.020^{\circ} \mathrm{C} / \mathrm{min}$ (Figure 9). The trend of the different R10-NR10 surface temperature is almost linear, and the heating contribution offered by the ribbon gradually increased to a maximum temperature of $3^{\circ} \mathrm{C}$ at $8.00 \mathrm{am}$. This temperature variation can be considered as the heating contribution offered by the ribbon to the pavement.

In the R6 area on the same day, the ribbon was activated at 4.38 am when the temperature in the $\mathrm{S} 12$ reference thermistor was $1.9^{\circ} \mathrm{C}$, and then it was turned off at $6.08 \mathrm{am}$ when the temperature at the same sensor reached $4.1^{\circ} \mathrm{C}$. In $\mathrm{R} 6$, the temperature variation on the ribbon recorded a value

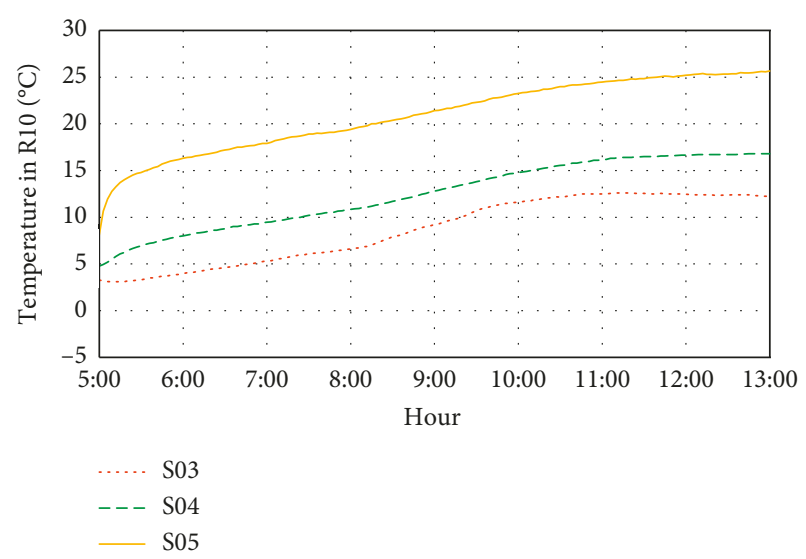

(a)

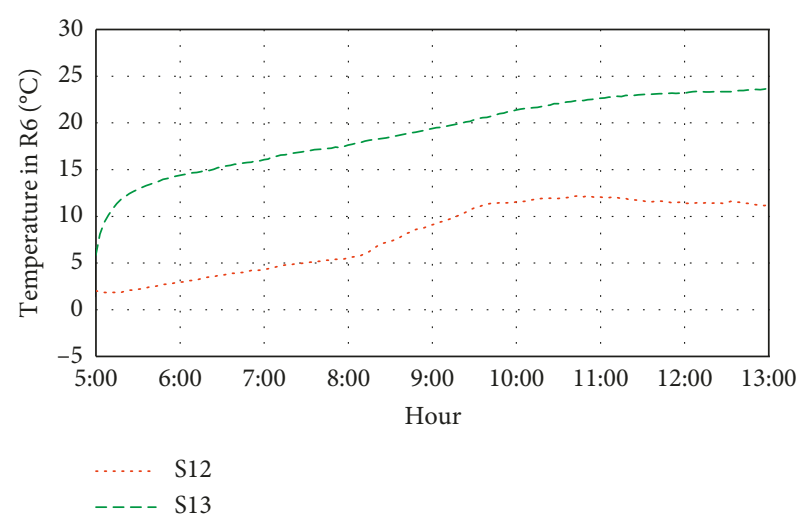

(b)

FIgURE 4: Temperature profile inside the pavement in R10 (a) and R6 (b), recorded by thermistors in S03, S04, and S05 and S12 and S13 from 5.00 to 13.00 , respectively.

of $12^{\circ} \mathrm{C}$ with a medium surface thermal rate of $0.022^{\circ} \mathrm{C} / \mathrm{min}$ (Figure 10). The difference between surface temperatures in R6 and NR6 had a more variable trend and reached $2^{\circ} \mathrm{C}$ when the ribbon was switched off. The maximum heating contribution offered by the presence of the ribbon in the pavement is therefore equal to $1.8^{\circ} \mathrm{C}$.

\section{Conclusions}

The numerous tests conducted on the heating ribbons and the study of the temperatures recorded during their activation facilitated an in-depth comprehension of their field performance. It should be noted that the presented experimental work was limited to the trial site at the International Airport of Bologna, during relatively harsh cold winter weather conditions.

The conception of the heating system allows the ribbons to be automatically activated based on set temperature (lower/higher) values. This keeps the pavement surface temperature above the freezing point, in order to prevent ice formation on the pavement itself, while keeping energy consumptions to a minimum. This was proven in the local weather conditions of the trial site, where the heating system was shown to prevent unsafe infrastructure conditions, 


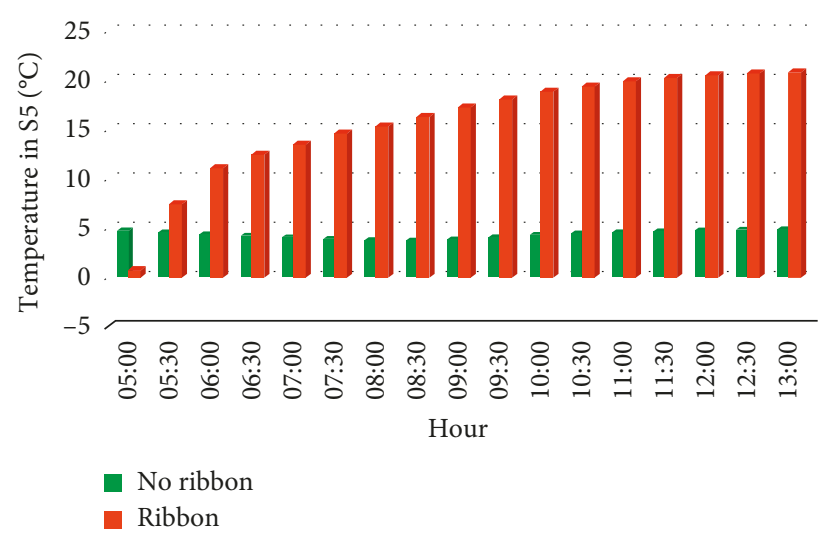

(a)

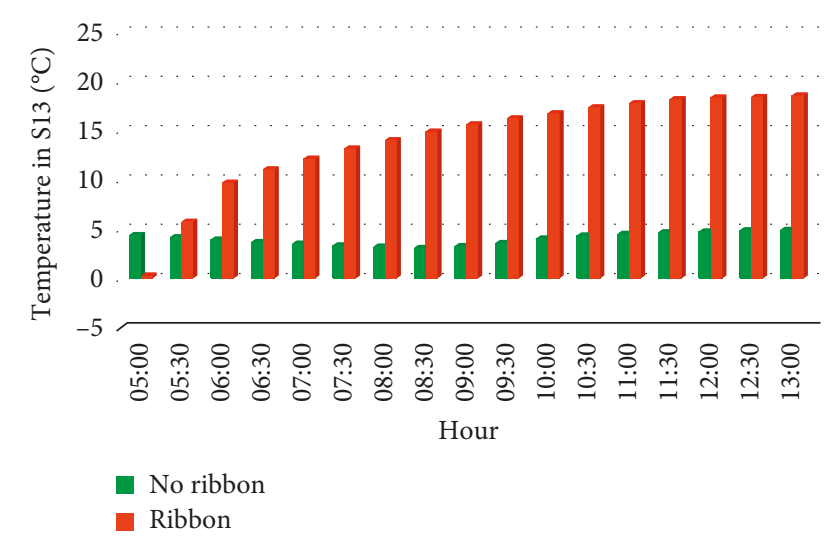

(b)

Figure 5: Heating contributions on pavements in S5 and S13, averaged in 30-minute intervals, from 5:00 to 13:00.

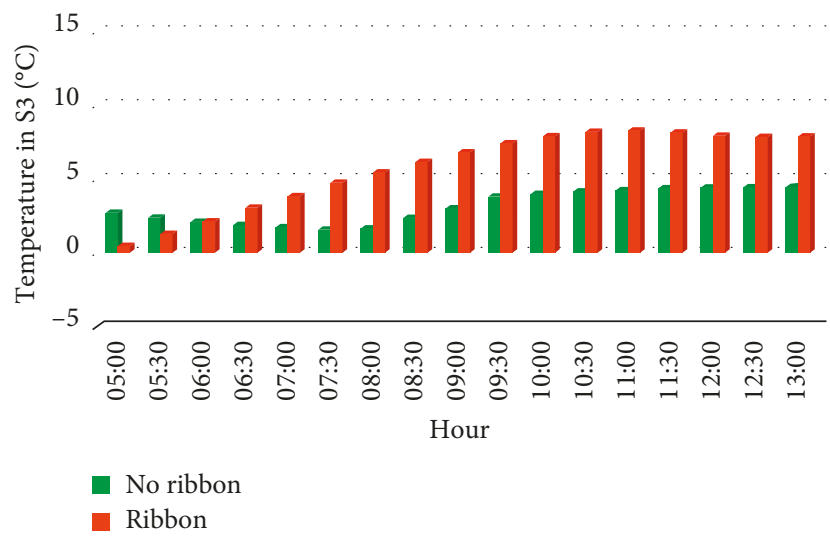

(a)

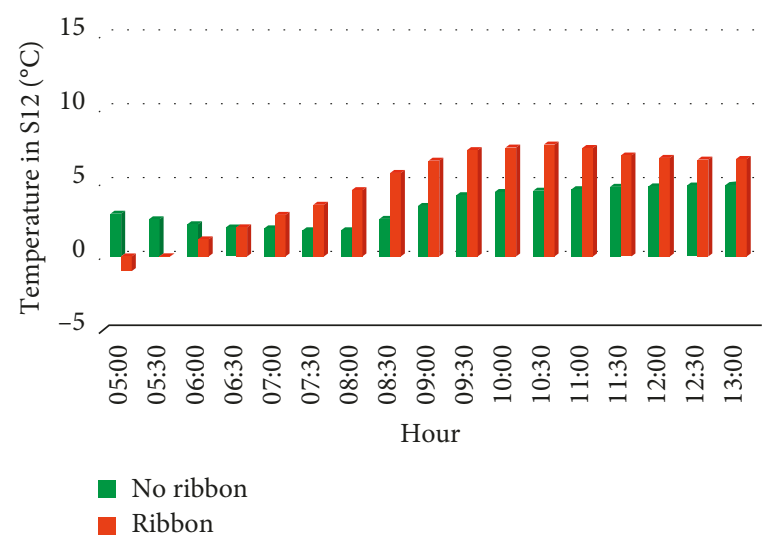

(b)

FIgURE 6: Heating contributions on the pavement in S3 and S12, averaged in 30-minute intervals, from 5:00 to 13:00.

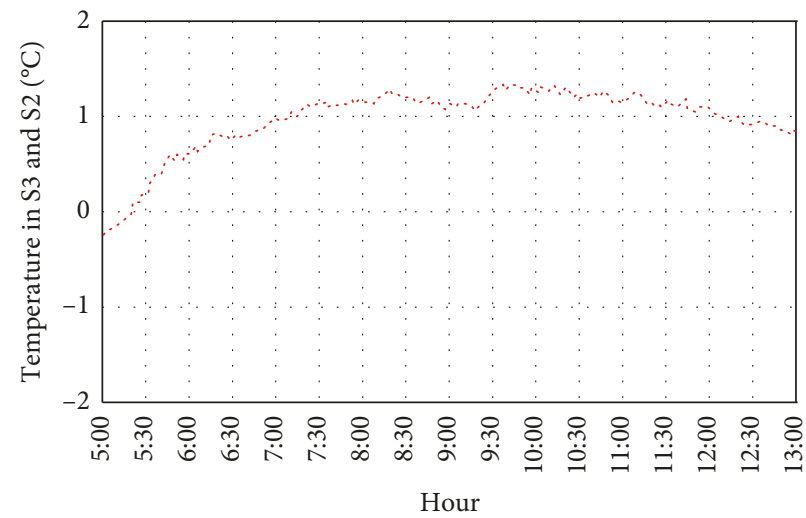

(a)

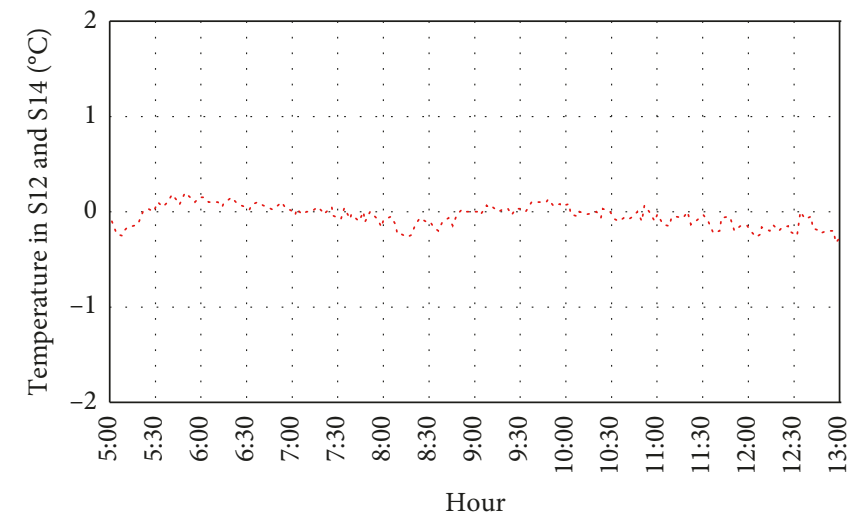

(b)

Figure 7: Differences between the temperatures recorded by the thermistors placed in S3 and S2 (a) and S12 and S14 (b).

bringing considerable benefits both to the safety of users and to the pavement conditions regarding possible thermally induced cracking.

According to the presented results, the main variables influencing the performance of the heating ribbons are the depth of installation, the type of asphalt concrete, the ribbon power, and the local weather conditions. These variables will have to be taken into account during the heating system design and installation; nevertheless, depths of 6 to $10 \mathrm{~cm}$ are recommended if surface milling operations are foreseen 


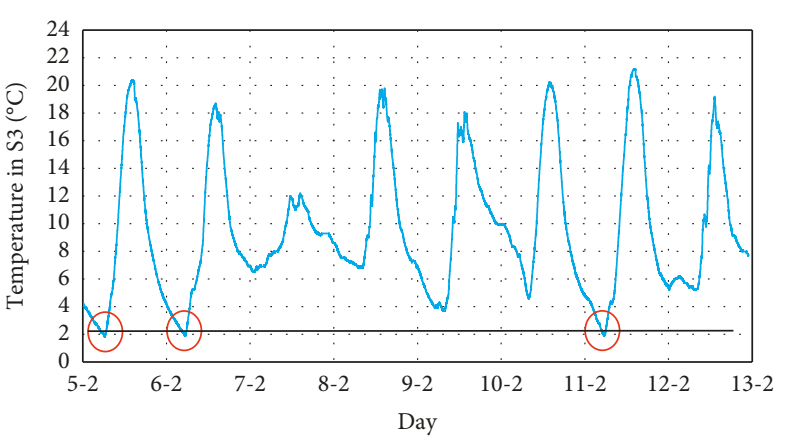

(a)

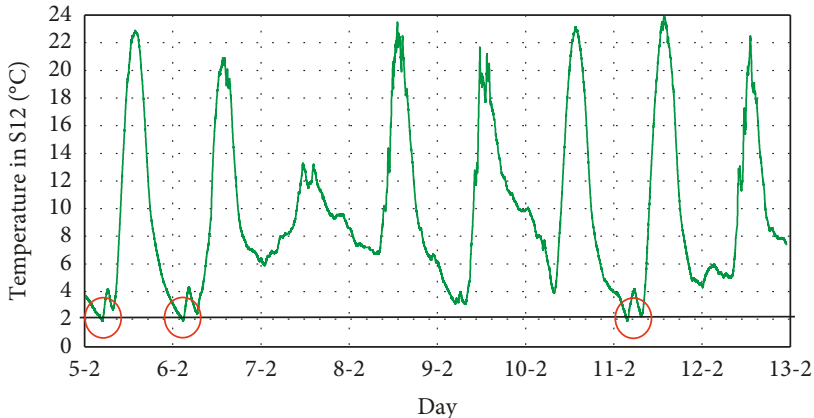

(b)

FIgURE 8: Surface temperatures recorded by sensors in (a) S3 and (b) S12.

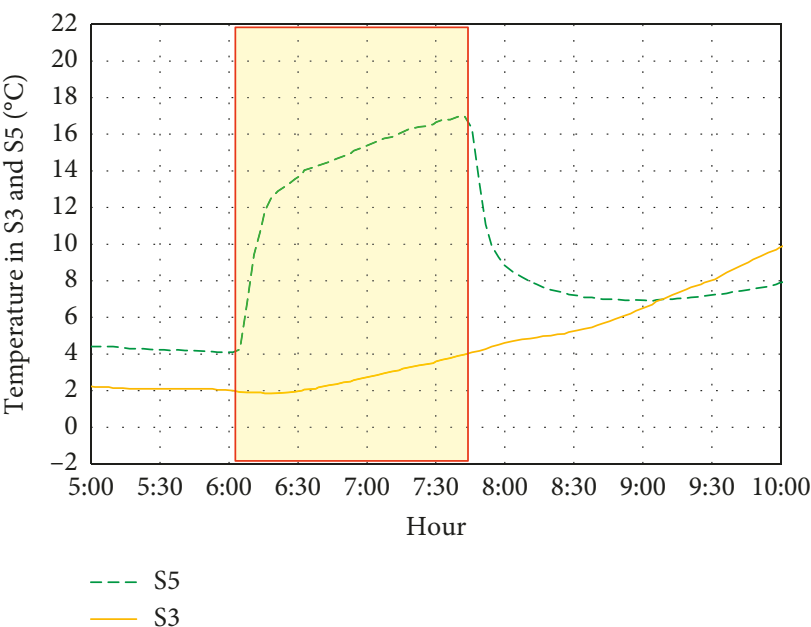

(a)

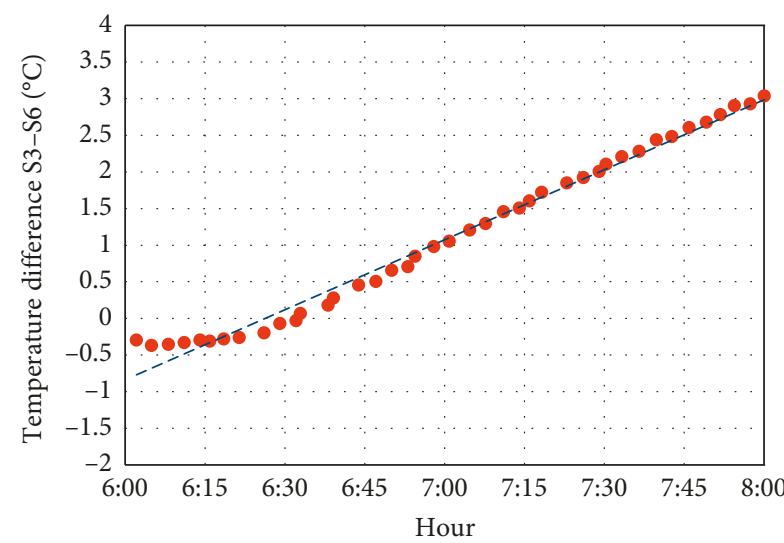

- $T$ difference

--- Linear trend

(b)

FIGURE 9: (a) S3 (surface) and (b) S5 (ribbon) temperatures and temperature difference recorded on the surface between R10 and NR10.

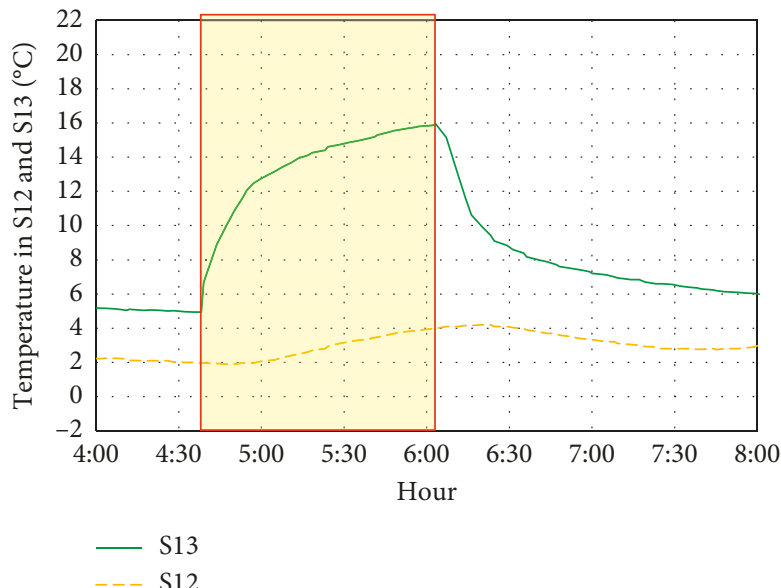

(a)

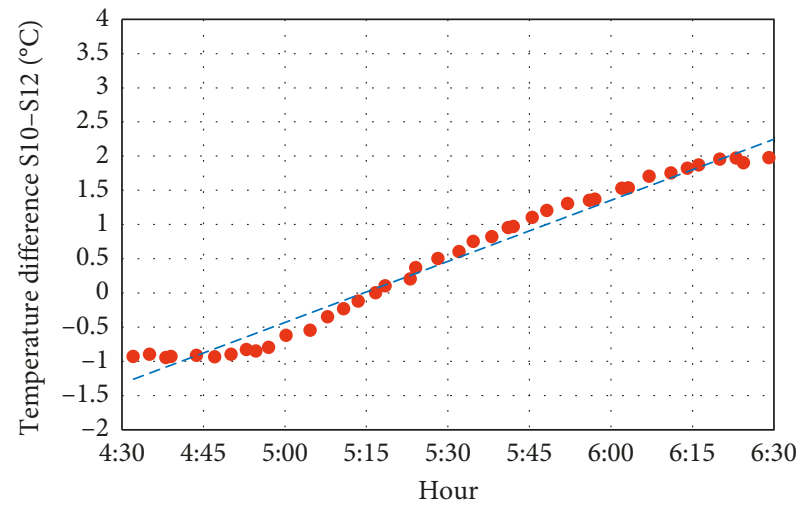

- $T$ difference

- - - Linear trend

(b)

FiguRE 10: (a) S12 (surface) and (b) S13 (ribbon) temperatures and temperature difference recorded on the surface between R6 and NR6.

during the pavement life. The difference between performances detected in the two depths in analysis has obtained similar values, so they are both usable. Finally, it should be noted that a valid surface temperature sensor should be adopted and calibrated in order to correctly trigger the ribbon activations. 
Based on the results of the research, the use of this type of technology can be considered in relatively small areas to increase the safety of mobility (e.g., sidewalks, bike lanes, ramps, motorway tolls, service stations, airport aprons, and taxiways). The durability study of these devices over a longer period of time and their maintenance will be addressed in future researches to improve the existing technology and their infrastructure applications.

\section{Data Availability}

The data used to support the findings of this study are available from the corresponding author upon request.

\section{Conflicts of Interest}

The authors declare that there are no conflicts of interest regarding the publication of this paper.

\section{References}

[1] D. Christensen, J. Mallela, D. Hein, E. Kalberer, M. Farrar, and R. Bonaquist, "Effect of deicing and anti-icing chemicals on HMA airfield runways," in Proceedings of FAA Worldwide Airport Technology Transfer Conference, Atlantic City, New Jersey, USA, April 2010.

[2] K. Walus and Z. Olsezwski, "Analysis of tire-road contact under winter conditions," in Proceedings of World Congress on Engineering 2011 Vol III WCE 2011, London, U.K, July 2011.

[3] X. Yuanni, J. Van Ommeren, P. Rietveld, and W. Verhagen, "Railway infrastructure disturbances and train operator performance: the role of weather," Transportation Research Part D: Transport and Environment, vol. 18, pp. 97-102, 2013.

[4] Transportation Research Board, Impact of Airport Pavement Deicing Products on Aircraft and Airfield Infrastructure, Synthesis 6, ACRP Airport Cooperative Research Program, Washington, DC, USA, 2008.

[5] A. Montepara, F. Giuliani, and S. Rastelli, "Modello di previsione della fessurazione termica delle pavimentazioni stradali flessibili," in Proceedings of SIIV Conference 2002, Melbourne, Victoria, Australia, October 2002.

[6] J. Kliewer, H. Zeng, and T. Vinson, "Aging and lowtemperature cracking of asphalt concrete mixture," Journal of Cold Regions Engineering, vol. 10, no. 3, pp. 134-148, 1996.

[7] M. Marasteanu, X. Li, T. Clyne, V. Voller, D. Timm, and D. Newcomb, Low Temperature Cracking of Asphalt Concrete Pavements, Minnesota Department of Transportation, Saint Paul, MN, USA, 2004.

[8] R. Velasquez and H. Bahia, "Critical factors affecting thermal cracking of asphalt pavements: towards a comprehensive specification," Road Materials and Pavement Design, vol. 14, no. 1, pp. 187-200, 2013.

[9] X. Shi, M. Akin, T. Pan, L. Fay, Y. Liu, and Z. Yang, "Deicer impacts on pavement materials: introduction and recent developments," The Open Civil Engineering Journal, vol. 3, no. 1, pp. 16-27, 2009.

[10] Y. Hassan, A. O. Abd El Halim, A. G. Razaqpur, W. Bekheet, and M. H. Farha, "Effects of runway deicers on pavement materials and mixes: comparison with road salt," Journal of Transportation Engineering, vol. 128, no. 4, pp. 385-391, 2002.

[11] S. Corsi, S. Geis, J. Loyo Rosales et al., "Characterization of aircraft deicer and anti-icer components and toxicity in airport snowbanks and snowmelt runoff," Environmental Science and Technology, vol. 40, no. 10, pp. 3195-3202, 2006.

[12] Y. Gao, L. Qu, L. Qu et al., "Study on effectiveness of anti-icing and deicing performance of super-hydrophobic asphalt concrete," Construction and Building Materials, vol. 191, pp. 270-280, 2018.

[13] C. Peng, P. Chen, Z. You et al., "The anti-icing and mechanical properties of a superhydrophobic coating on asphalt pavement," Construction and Building Materials, vol. 190, pp. 83-94, 2018.

[14] H. Wei, Q. He, Y. Jiao, J. Chen, and M. Hu, "Evaluation of anti-icing performance for crumb rubber and diatomite compound modified asphalt mixture," Construction and Building Materials, vol. 107, pp. 109-116, 2016.

[15] W. Eugster, "Geothermal snow melting and de-icing," in Proceedings European Geothermal Congress 2007, Unterhaching, Germany, May-June 2007.

[16] A. Balbay and M. Esen, "Temperature distributions in pavement and bridge slabs heated by using vertical groundsource heat pump systems," Acta Scientiarum. Technology. Maringá, vol. 35, no. 4, pp. 677-685, 2013.

[17] J. Lund, Pavement Snow Melting, Geo-Heat Center, Oregon Institute of Technology, Klamath Falls, OR, USA, 2007.

[18] FAA AC No: 150/5370-17, Airside Use of Heated Pavement Systems, U.S.Department of Transportation, Washington, DC, USA, 2011.

[19] A. Balbay and M. Esen, "Experimental investigation of using ground source heat pump system for snow melting on pavements and bridge decks," Scientific Research and Essays, vol. 5, no. 24, pp. 3955-3966, 2010.

[20] R. Van Wijk, C. Sangiorgi, and F. Baroncini, "Novel Heating Technologies to Control the Surface Conditions of Pavements," in Proceedings of E\&E Congress 2016, 6th Eurasphalt \& Eurobitume Congress, Prague, Czech Republic, June 2016.

[21] C. Laforte and M. M. Tremblay, "Comparative evaluation of the anti-icing protection time of runway deicers using infrared thermography," Cold Regions Science and Technology, vol. 138, pp. 57-62, 2017. 


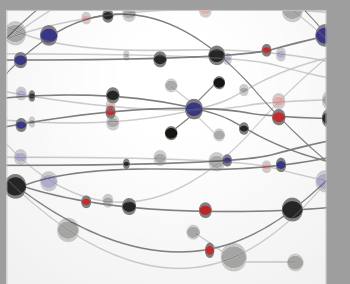

The Scientific World Journal
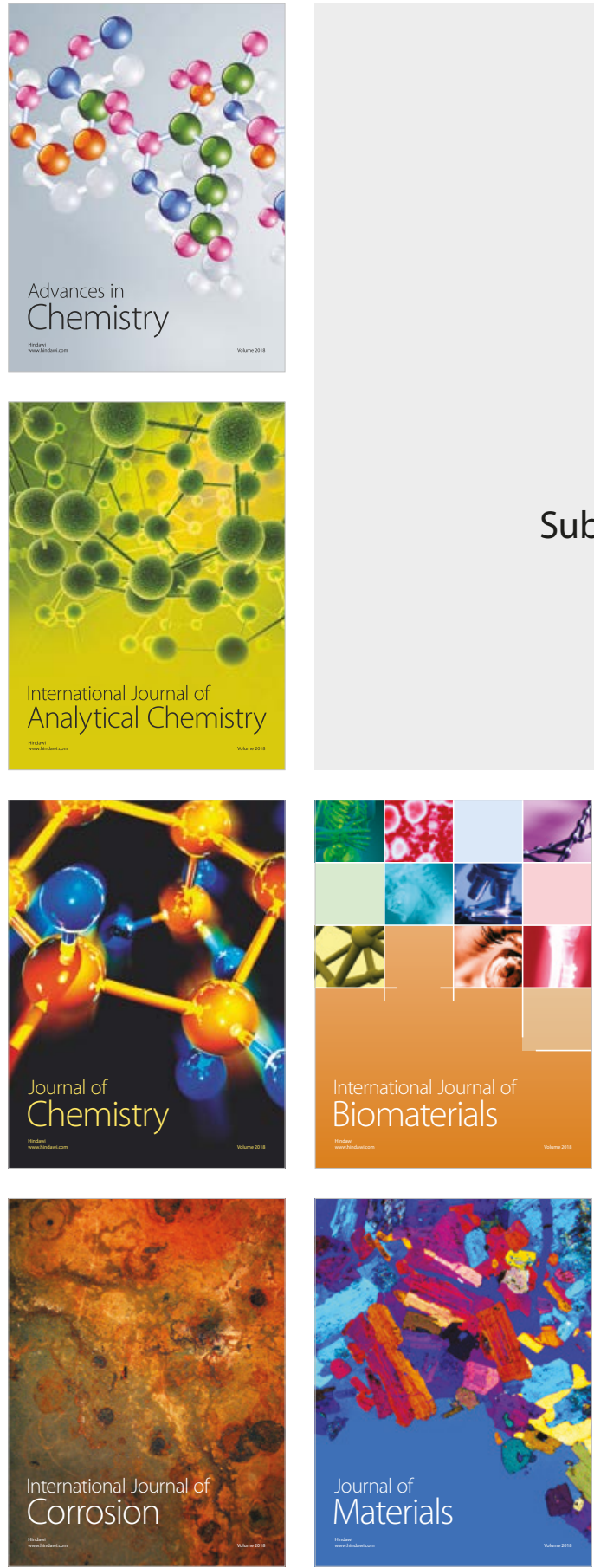

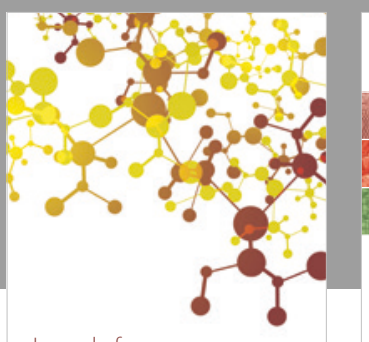

Journal of

Applied Chemistry
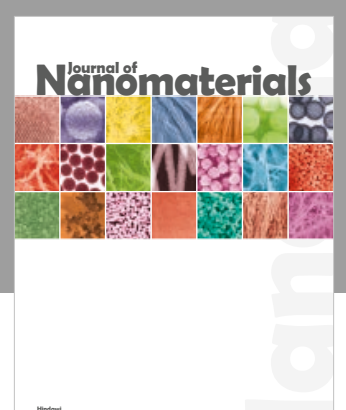

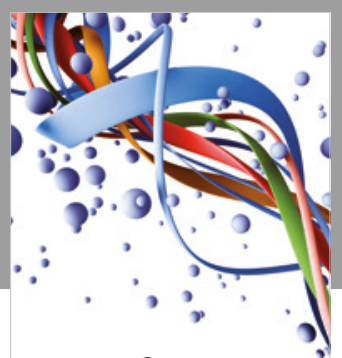

Scientifica

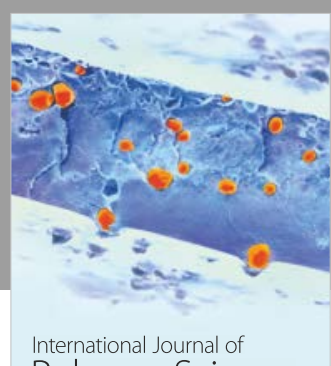

Polymer Science

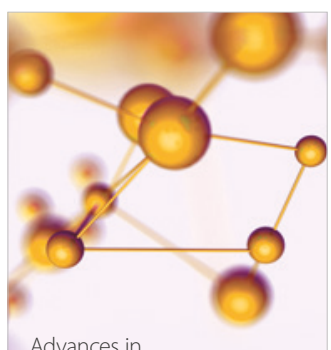

Physical Chemistry
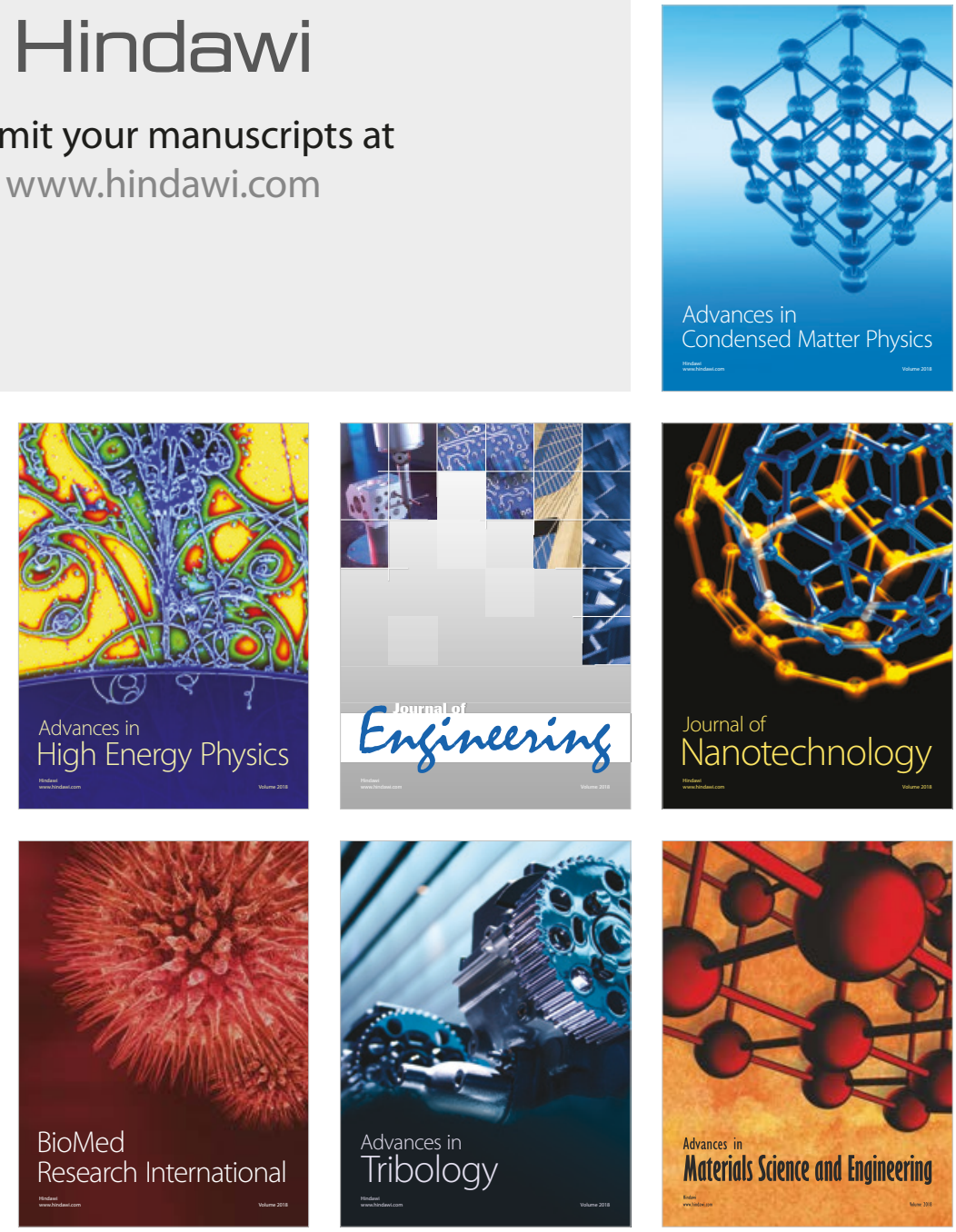